\title{
Public Health Observatories - the key to timely public health intelligence in the new century
}

One of the proposals in the British Our Healthier Nation public health strategy is that " ... in order to strengthen the availability and use of information about health at the local level we will ensure that there is a Public Health Observatory in each ... region of the country." These observatories will be closely linked with universities to help bring an academic rigour to their work. Their tasks will be to support local bodies by:

- Monitoring health and disease trends and highlighting areas for action.

- Identifying gaps in health information.

- Advising on methods for health and health inequality impact assessments.

- Drawing together information from different sources in new ways to improve health.

- Carrying out projects to highlight particular health issues.

- Evaluating progress by local agencies on improving health and cutting inequality.

- Looking ahead to give early warning of future public health problems. ${ }^{1}$

The need for such a different approach for the provision of public health intelligence had been identified in the North West of England in 1990 by the establishment of the Liverpool Public Health Observatory within the University of Liverpool Medical School by the Mersey Regional Health Authority. ${ }^{2}$ As caricatured at the time, the problem of conventional funding of research and intelligence from the universities was seen as being their tendency to wish to take the funding and disappear for three to five years, only coming back with the answer when the question had changed! Questions needing answering in days, weeks or months rather than months and years did not fit in with the universities' research timetable, self assessment and rating scales and did not seem to be valued. At the same time public bodies as well as NGOs needed robust and reliable intelligence to shape policy options and decisions. The alternative of free floating consultants often proved shallow, disconnected and ephemeral. Was there not scope for a win-win situation by packaging the work that needed to be done within an academic environment but with contractual safeguards so that the needs of all stakeholders could be met?

The Liverpool Observatory had as its mission statement: “. . . to generate and evaluate the application of public health intelligence in collaboration with the University Department of Public Health and other agencies, groups and individuals

1 by anticipating and responding to clients' public health intelligence needs,

2 by supporting development of the public health and related organisations,

3 by acting as a focus for maximising the cross-fertilisation of experience and skills between academic and service public health to develop and maintain methodological rigour."

The notion of an "observatory" was taken to convey standing back from phenomena and events and providing description, analysis and forecasting of patterns, interrelationships, processes and outcomes. The organisational model was influenced by the existence of observatories in some other European countries, notably France and Italy. For example, in Italy the "Osservatorio Epidemiologico" is basically a surveillance centre at the regional level. They usually began as centres specialised in one particular disease (usually chronic) or environmental hazard. In more recent years they have tended to become linked to Regional Health Authorities to help form health policy (Bruisin S, personal communication).

Since 1990, the Liverpool Observatory has been involved in an extensive range of work (see box).

This idea of developing health intelligence has had some important other strands, not least the proposal by Kerr-White and colleagues that each medical school should have a centre for health intelligence linked to the Dean's office where it could influence the education and training of students by matching curriculum to local population health needs. ${ }^{34}$ More recently, the World Health Organisation has established the European Observatory on Health Systems, ${ }^{5}$ with links between the World Health Organisation and a number of academic centres; the aim is to promote the development of evidence-based health policy.

So what will the new British Regional Public Health Observatories look like once they are established this year? The eight British Health Regions typically have populations of five to eight million people. What is envisaged is a comprehensive network of observatories and intelligence sources, which is integrated both vertically and horizontally, which looks both inwards to organisational objectives and goals and outwards to an information empowered population and which focuses on the understanding of current, emerging and future health and health and social care needs of people and investments for health in terms of both geographical area and community of interest. At the national level there will be links to the newly formed Health Development Agency with its responsibility to build health capacity together with relevant government departments and other agencies and stakeholders. At the regional level, observatories will be responsible for ensuring that complete pictures of population health and health and social care needs are available, building on the reports of district Directors of Public Health, cancer registries, other sources of health intelligence and links with the intelligence units of the newly evolving regional layer of devolved government, including Regional Development Agencies, revitalised local government and the voluntary sector. At the local level the emerging Primary Care Trusts, which are charged with public health development, ensuring the pro-

\section{Liverpool Public Health Observatory}

EXAMPLES OF TOPICS COVERED SINCE 1990 INCLUDE

- planned parenthood

- family planning, abortion and fertility

- coronary heart disease and stroke

- drug misuse and drug misuse services

- alcohol abuse; needs assessment and services review

- deafness

- asthma and environmental pollution

- environmental causes of death and disability

- tuberculosis and poverty

- cystic fibrosis and deprivation

- health impact assessment of the Merseyside Integrated Transport Strategy 
vision of high quality primary health and social care and commissioning secondary care, will become the basic epidemiological building block for populations of 100000 to 200000 people-developing the intelligence function at this level and integrating it into the observatory function will be a particular challenge and may require some statutory basis. Of particular importance will be for observatories to get ahead of the game by looking forward to give early warning of threats to public health through prediction and scenario planning, highlighting areas for concern and action and drawing together information from different sources.

As we enter the third millennium, the observatory concept and metaphor seems especially appropriate for a pro-active and effective public health movement. In the past 100 years, public health has gone from a predominantly local focus to an increasingly global one. Globalism may already seem a cliché, but if we are to be fit for the purpose to respond to threats to public health we need intelligence systems that are integrated horizontally and vertically at all key levels, whether global or local. The proposed observatories should be looking at health conditions both metaphorically and in reality, communing with the way society is. Perhaps the regional model that is emerging will provide the building blocks for such a system across Europe and beyond?

JOHN R ASHTON, CBE

NHS Executive North West, 930-932 Birchwood Boulevard, Millennium Park, Birchwood, Warrington WA3 7QN (jech@liverpool.ac.uk)

1 Department of Health. Saving lives-our healthier nation. London: The Stationery Office, 1999. Cm 4386.

2 Hotchkiss J, Mooney G, eds. Liverpool Public Health Observatory Research Review, 1990-1994. Liverpool: Department of Public Health, University of Liverpool, 1995.

3 White Kerr L. Healing the schism-epidemiology, medicine and the public health. Berlin: Springer-Verlag, 1991.

4 White Kerr L, Connelly JE. The medical school's mission and the population's health. New York: Springer-Verlag, 1992.

5 Richards T. European observatory will promote better health policy. BMF 1999;318:352. 